\title{
Earthquake risk assessment of lifelines
}

\author{
Kyriazis Pitilakis • Maria Alexoudi • \\ Sotiris Argyroudis • Olivier Monge • \\ Christophe Martin
}

Received: 3 December 2005 / Accepted: 3 August 2006/

Published online: 20 September 2006

(C) Springer Science+Business Media B.V. 2006

\begin{abstract}
This paper presents the RISK-UE methodology for the seismic risk assessment of utility systems (potable water, waste-water, gas system, telecommunication, electric power) and transportation infrastructures (port, airport, road and railway system). The proposed methodology provides a uniform basis for the reduction of the consequences of lifeline damages in urban areas and an efficient mitigation strategy and prioritization policies for pre-earthquake and post earthquake actions. A detailed inventory for every element at risk together with a reliable seismic hazard assessment, appropriate selection of fragility models, estimation of the "global value" and economical impact of lifeline damages and losses are the main steps of the proposed methodology. The consideration of European distinctive features of lifelines and utility systems in the construction of seismic scenarios and the proposition of fragility curves are among the basic aims of the proposed methodology. Different modules of the methodology were applied in seven pilot cities (Thessaloniki, Catania, Nice, Bucharest, Sofia, Barcelona, Bitola). We present herein few representative examples (case studies) in order to illustrate the methodology and to prove its efficiency.
\end{abstract}

Keywords RISK-UE · Lifelines · Utility systems · Seismic hazard · Risk · Mitigation · Inventory · Vulnerability

\section{Introduction}

Lifelines are vital for the community as they supply energy and fresh water, treat the waste water and provide transportation and communication services to inhabitants.

K. Pitilakis $(\varangle) \cdot$ M. Alexoudi · S. Argyroudis

Department of Civil Engineering, Aristotle University of Thessaloniki, POB 450, 54124,

Thessaloniki, Greece

e-mail: kpitilak@civil.auth.gr

O. Monge $\cdot$ C. Martin

GEOTER International, Roquevaine, France 
Their role is even more important in modern developed societies where living conditions, the economic, cultural and social activities are fully depended on a complex network of lifelines. In addition, the seismic protection of urban areas with high population density, substantial residential building growth and important administrative, commercial and industrial activities dictates a reliable assessment of the associated seismic vulnerability and the establishment of a reliable risk mitigation strategy for lifelines.

In Europe few efforts have been made so far to develop a reliable methodology to evaluate the vulnerability indexes for lifelines systems (i.e., water) and to assess the vulnerability of specific lifeline components within urban areas exposed to seismic risk. The lack of numerous European researches on this issue is inversely promotional to the high seismicity of certain areas especially in the south part of Europe, the extreme complexity, the spatial extent and interdependencies between the networks and the urban environment, their spatial variability and differences in typology from one country to another, the difficulty to establish a reliable and complete inventory and the difficulties in sharing necessary information and data, even if the specific network plays an important role in the security and health of citizens, has been also contributed to this lack of specific research studies. Considering all these difficulties and the inherent uncertainties in the assessment of seismic hazard, the definition and description of urban characteristics, the construction of fragility curves for all components and sub-components of all lifeline systems, RISK-UE project "An advance approach to earthquake risk scenarios with applications to different European towns" financed by the European Commission is a major step toward the development of a European methodology to assess and mitigate the seismic risk of lifelines and essential facilities in Europe. RISK-UE project was entrusted to synthesize the available European knowledge and know-how in lifeline earthquake engineering, to collect damage data and information of lifelines inventory (water, waste-water, gas, telecommunication, electric power, roads, railways systems, port, airport) of seven characteristic European cities, to classify the available information, to provide if possible an European typology and to develop a lifeline seismic risk assessment methodology according to European specific features of lifelines, urban fabric characteristics and seismic hazard assessment. RISK-UE reflects the European know-how, expertizes different ways of facing issues regarding loss estimation and risk mitigation and should be considered as a first step in the development of a coherent and unified European approach.

Emphasis was given to the synergies between urban environment and lifelines in normal, crisis and recovery period. The combination of lifelines importance through a "global value" approach, the vulnerability assessment of lifelines and the seismicity for three operation periods provide in RISK-UE the necessary mitigation strategy. References and discussion are made with other world-wide methodologies (e.g., ATC13, HAZUS).

In the present stage of RISK-UE development, there isn't any software development similar to Hazus, although GIS platform was used in each step of the methodology. While network analysis (connectivity, serviceability) was not initially foreseen in some specific networks and pilot cities such analyses were made (i.e., connectivity analysis for Thessaloniki gas system, rough serviceability analysis for Thessaloniki water network, serviceability of the roadway network in Catania). The paper presents the main steps of the RISK-UE methodology through the presentation of typical examples. More details and thorough discussion on many methodological aspects 
may be found in the RISK-UE final technical report for lifelines (Monge et al. 2004), as well as in Pitilakis et al. (2005a).

\section{Methodology}

In the last years, several methodologies were introduced for lifeline risk assessment in urban environment aiming to minimize losses, enhance the reliability of the systems and improve mitigation policies. Moreover, a variety of hazards were considered (earthquakes, floods, wind, ice-storms, tornados, etc) along with different hazard scenarios, different recurrence period and in some cases different aspects of uncertainty. Scawthorn et al. (1999), Reed and Cook (1999) and Seligson (2003) have introduced methodologies for water and waste-water system, while Ballantyne et al. (1999), Huyck et al. (2003) and Chang and Seligson (2003) for power supply systems. Modular methodologies for specific networks were developed as well. For example, Werner et al. (2000) developed a methodology for the seismic risk assessment of highway networks, including models for transportation network analysis, hazard estimation, seismic performance of highway components and evaluation of the economic impact. A similar methodology for highway system was proposed by Kiremidjian et al. (2003). Pachakis and Kiremidjian (2004) proposed a model to assess probabilistically the operational losses of container ports for different seismic scenarios.

Multi-hazard methodology tools were recently introduced to evaluate the vulnerability and the performance of lifelines under a variety of natural and technological hazards. HAZUS (NIBS 1999, 2004) is a typical example of an advanced GIS multihazard methodology.

RISK-UE is intended to be a unified earthquake risk assessment methodology considering the distinctive features of European towns with their real building stock of modern and historical buildings, together with lifelines and essential facilities. Weak points of urban systems are evaluated through detailed seismic hazard assessment including local soil conditions, and complete the inventory databases of all elements at risk. For selected seismic scenarios direct and indirect damages are calculated mainly for the building stock.

The overall approach of RISK-UE methodology for lifelines is presented in Fig. 1. It highlights the various modules and their interconnections (Pitilakis et al. 2005a). The following presentation is articulated on the basis of this flowchart.

\section{Description - inventory}

The general description of each particular lifeline network provides an illustration of the overall system and the direct or indirect relations and connection links between components and subcomponents. As an example, a first level breakdown of a railway transportation system is given in Table 1 . Based on the description scheme the next crucial step is the elaboration and development in GIS format of the detailed inventory of all components.

The inventory of each network includes the description of the distinctive features of the different components (e.g., geometry, material, age, etc) and the definition of their typology. Within RISK-UE project, descriptive templates and catalogues with available information for every element at risk of lifelines were produced. The proposed 


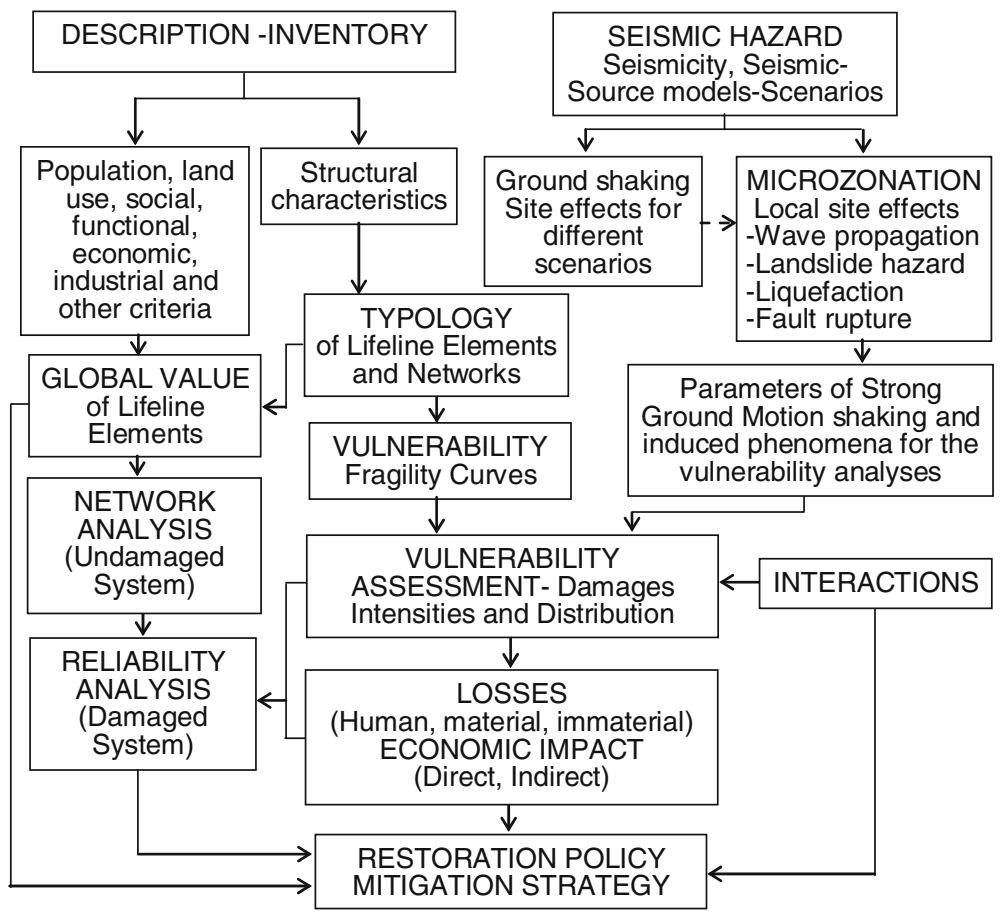

Fig. 1 Flowchart of RISK-UE methodology

Table 1 Breakdown of a typical railway transportation system

\begin{tabular}{lll}
\hline Rolling Stock & Railway Facilities & Railroad Infrastructure \\
\hline Buildings & Specific infrastructures \\
- Terminal stations; & -Bridges; \\
- Maintenance; & - Tunnels; \\
- Control house; & - Retaining walls; \\
- Administrative & - Overpasses; \\
& - Drainage systems \\
& Utilities & Track's installations \\
- Electric power; & - Level crossings; \\
- Fuel facilities; & - Signaling; \\
- Water/Waste water & - Electro-motion; \\
- Gas & - Telecommunication \\
& Tracks \\
\hline
\end{tabular}

inventories (Monge et al. 2004) are a synthesis and enhancement of similar inventory databases, initially developed for the seismic risk assessment of lifelines in USA (ALA 2002; NIBS 1999, 2004; ATC-13 1985 etc) and adequately adapted to consider the European distinctive features. A representative example of such questionnaire is given below for the water-pipelines (Table 2).

Based in the above inventory catalogues, all relevant data should be collected for the lifeline networks in each city, and incorporated in a GIS platform. The accurate description of the distinctive features in the light of the seismic risk evaluation is 
Table 2 Inventory for water system (RISK-UE methodology)

Detailed inventory for water pipelines

General information:

Geographic location (coordinates), Location of pressure reduction valves (coordinates), Exact location of connections (coordinates), Location of manhole (central, smaller), Location of isolation valves, of SCADA, In case of failure: Isolation of pipe segments (area coverage, number of customers).

Geometrical and construction details:

Length (m), Type (fragile, ductile), Diameter ( $\mathrm{mm}$ ), Thickness ( $\mathrm{mm}$ ), Elevated or buried, Material, Strain: $\sigma \mathrm{y}, \sigma \mathrm{f}(\mathrm{Mpa})$, Connection type (compression coupling, bell \& spigot, heat fusion, arc or oxyacetylene gas weld), Rotation tolerance, Depth (m), Type of coating, Type of lining, Type of protection material (if any), Operational characteristics (free-flow, with pressure), Operation pressure (atm), Directivity of flow, Year of construction, Corrosion (yes, no, possible, unknown), Description of construction technique, History of failures/ repairs (not only from earthquakes but also from operation use), Method of repair.

Urban \& economic characteristics:

Type of customers served (important, common), Connection with essential/critical facilities (e.g., hospitals, clinics etc), Alternative routing, Time of emptying pipe segment, Economic cost of construction, Cost of reconstruction if damaged by an earthquake.

\section{Basic features of water pipelines}

Geographic location, Diameter, Thickness, Material, Connection type, Operational characteristics, Distances between connections, Type of customers served, Connection with essential/critical facilities, Description of construction technique, Alternative routing, Location of manhole, Location of valves, isolation valves etc, Location of SCADA, Economic cost of construction.

an important step for the definition of the typology. A typical example is shown in Fig. 2 for the water system of Thessaloniki. However, several difficulties arise in the collection and archiving of the data, related to the aging of networks (unknown location, material etc), digitization process, competition between the lifeline managing companies, security issues or even unwillingness of lifeline owners to provide data.

\section{Typology}

Until RISK-UE there was no European typology for lifelines. RISK-UE methodology provided the basis for the definition of typology for each lifeline element at risk that is essential for the vulnerability analysis. Through the collection of the inventory information in the seven cities representing different countries and construction practices, mean typology characteristics of lifelines were derived. The final selection took also into consideration the typology found in bibliography. A typical example for water systems is given in Table 3. Detailed typology description for all components and lifelines may be found in Monge et al. (2004).

\section{Seismic hazard}

Damages to lifeline elements and systems are caused by ground shaking, large permanent ground deformation and ground failure or combination of them. Most of the damages to pipelines are normally reported when a pipeline is crossing soils with substantial impedance contrast. Consequently spatial variability of ground motion 

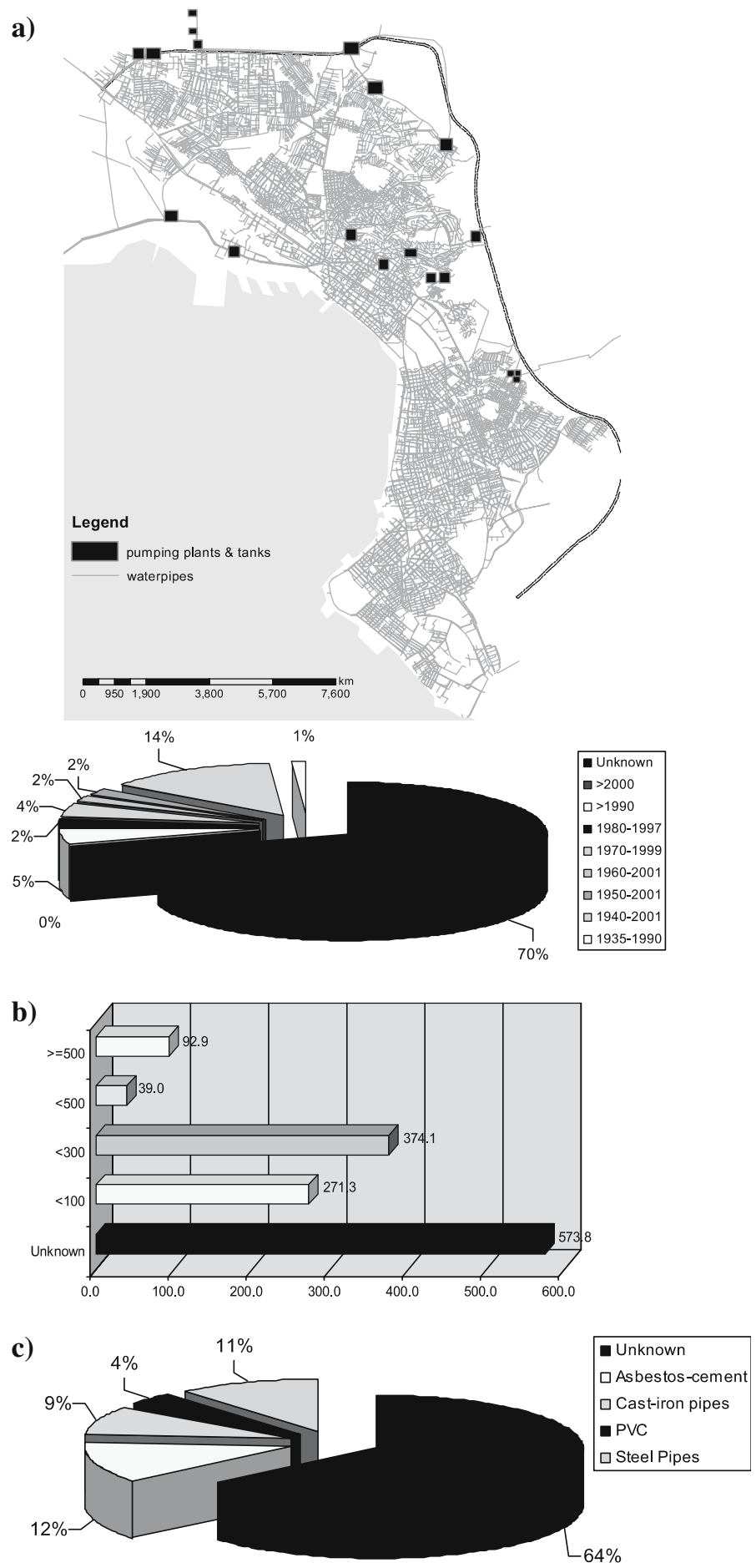

Fig. 2 Thessaloniki: Map of the water system in Thessaloniki and statistical data (a) construction year, (b) length of pipes according to diameter classes and (c) pipe material 
Table 3 Typology of element at risk for water system

\begin{tabular}{|c|c|c|c|}
\hline Element at risk & HAZUS (NIBS 1999, 2004) & $\operatorname{ALA}(2001 \mathrm{a}, \mathrm{b})$ & RISK-UE \\
\hline Pipes & Material (Ductile, Fragile) & $\begin{array}{l}\text { Material (Steel, PVC, PE, } \\
\text { etc) Diameter Type of } \\
\text { connection Soil conditions } \\
\text { (corrosive or dry) }\end{array}$ & $\begin{array}{l}\text { Similar } \\
\text { to ALA }\end{array}$ \\
\hline Tanks & $\begin{array}{l}\text { Material (steel, R/C, wood, } \\
\text { open-cut) Type of founda- } \\
\text { tion (elevated, at-graded, } \\
\text { buried) Type of anchorage } \\
\text { (yes, no) }\end{array}$ & $\begin{array}{l}\text { Material (steel, R/C, wood, } \\
\text { open-cut) Type of anchor- } \\
\text { age (yes, no) Type of } \\
\text { foundation (elevated, at- } \\
\text { graded, buried) Capac- } \\
\text { ity (small, medium, large) } \\
\text { Code level (high, low, no- } \\
\text { code) }\end{array}$ & $\begin{array}{l}\text { Material } \\
\text { (steel, R/C) } \\
\text { Type of } \\
\text { foundation } \\
\text { (elevated, } \\
\text { at-graded, } \\
\text { buried) } \\
\text { Type of } \\
\text { anchorage } \\
\text { (yes, no) }\end{array}$ \\
\hline Pumping station & $\begin{array}{l}\text { Size (small, medium, large) } \\
\text { Type of anchorage (yes, no) }\end{array}$ & - & $\begin{array}{l}\text { Similar } \\
\text { HAZUS }\end{array}$ \\
\hline
\end{tabular}

and local soil conditions can alter greatly the performance of lifeline systems as a result of their large extend. The spatial distribution of seismic loading, due to wave propagation is described in terms of peak ground acceleration (PGA), spectral values of acceleration, peak ground velocity (PGV) or strains, while for permanent ground deformation and ground failure in terms of permanent ground displacement (PGD) or dislocation (i.e., fault rupture or extensive landslide). Intensity descriptors i.e., in MSK scale, usually applied in case of building's vulnerability are not adequate to describe lifeline damages.

In RISK-UE, for each element at risk, the appropriate parameter of seismic motion was defined according to the particular characteristics of the lifeline components and the state-of-the-art knowledge and practice regarding the seismic design of lifelines. For bridges the best descriptor is a response spectral value at a specific period (i.e., $T=1.0 \mathrm{~s}$ ) or the PGA values both accounting for local soil conditions. For other lifeline elements at risk it may be PGA (i.e., buildings, tanks, waterfront structures) or permanent ground deformations (i.e., embankments, roadways, railways). For pipelines, PGV has been proved to be better correlated to the observed damages and thus the vulnerability assessments must be based on peak or "effective" ground velocity estimates. Moreover, in an advanced approach for pipelines it should be necessary to consider the spatial distribution of ground longitudinal or/and transversal strains that can be derived only from systematic analyses of local site conditions and adequate seismic ground response analyses.

In case of urban sites, a systematic analysis of seismic ground response analysis is commonly referred as microzonation study (Mouroux et al. 2004, Pitilakis 2004). Specific geotechnical and surface geology information is required to estimate the necessary ground shaking or deformation parameters.

RISK-UE risk assessment methodology for lifelines, is a multi-level approach that can be applied according to the principal of an "acceptable level of damage". Defining the "acceptable damage", several definitions should be accounted according to economic prosperity of the country, the pre-defined safety level for each lifeline system, the international practice, and, the natonal laws and the codes. Considering the need 
of European harmonization regarding natural hazards mitigation and safety level a common acceptable risk should enact all over the European continent. However as, every element at risk is prone to specific seismic scenarios, probably with different return period according to its importance, the selection of the most appropriate or "worst" seismic scenario isn't a simple decision. In RISK-UE a uniform approach has been developed for the estimation of the earthquake ground shaking hazard and induced effects in urban areas. For details see the accompanying paper of Faccioli (2005) in this journal. Emphasis was placed on adopting homogenous criteria in the quantitative treatment of seismicity and in the construction of ground shaking scenarios, which are also depending on the level of detail of hazard in each city. It is also suggested that ground motion scenarios should be both of deterministic and constant hazard type, adapted for intensity based damage assessment using damage probability matrices (i.e., for buildings) and also for more sophisticated assessments as described above for lifelines or based on capacity curves for different classes of building.

A representative example of a high level hazard assessment with systematic 1D site specific ground response analysis for a probabilistic scenario with 475 years recurrence period is given for Thessaloniki in Figs. 3 through 7, illustrating detailed maps for peak horizontal ground acceleration (PHGA, Figs. 3, 4) for different spectral periods $(T=0.0 \mathrm{~s}$ and $1.0 \mathrm{~s}$ ), peak horizontal ground velocities (PHGV, Fig. 5), mean effective ground shear strains at $-3.0 \mathrm{~m}$ (Fig. 6), liquefaction associated settlements and horizontal lateral spreading displacements (Fig. 7). Similar maps for PHGA at $T=0.0 \mathrm{~s}$ are given for Catania (Fig. 8, Faccioli et al. 2004) and Barcelona (Fig. 9, Roca 2004). Special attention is given to the uncertainties associated with the seismic load and it was suggested that all seismic parameters must be estimated with a mean value \pm a standard deviation.

Fig. 3 Thessaloniki: Spatial distribution of mean peak horizontal ground acceleration $(T=0.0 \mathrm{~s})$

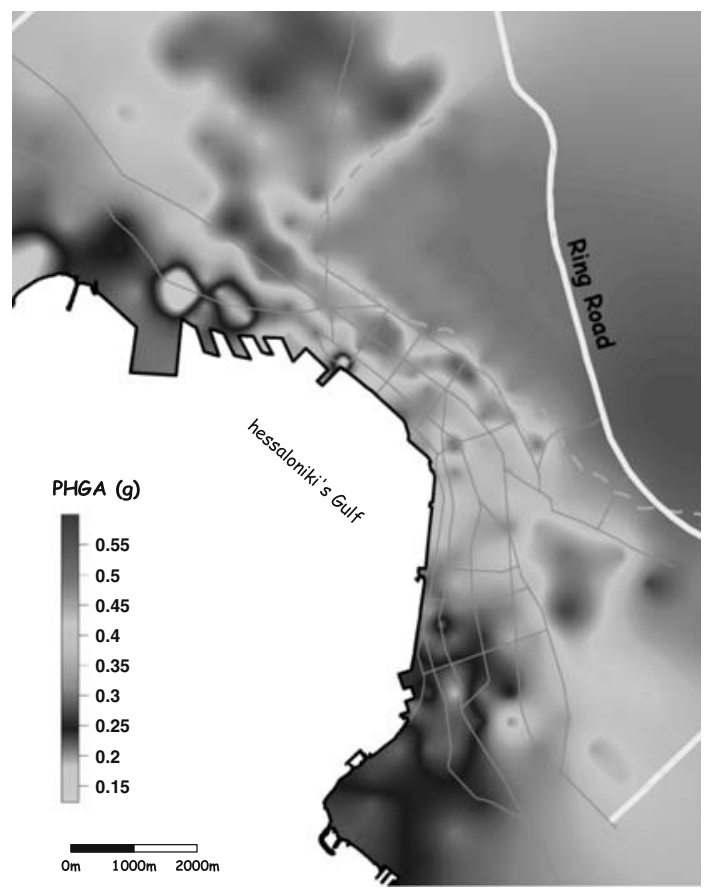


Fig. 4 Thessaloniki: Spatial distribution of mean peak acceleration $(\mathrm{g})$ at $T=1.0 \mathrm{~s}$
Fig. 5 Thessaloniki: Spatial distribution of peak horizontal ground velocities $(\mathrm{m} / \mathrm{s})$
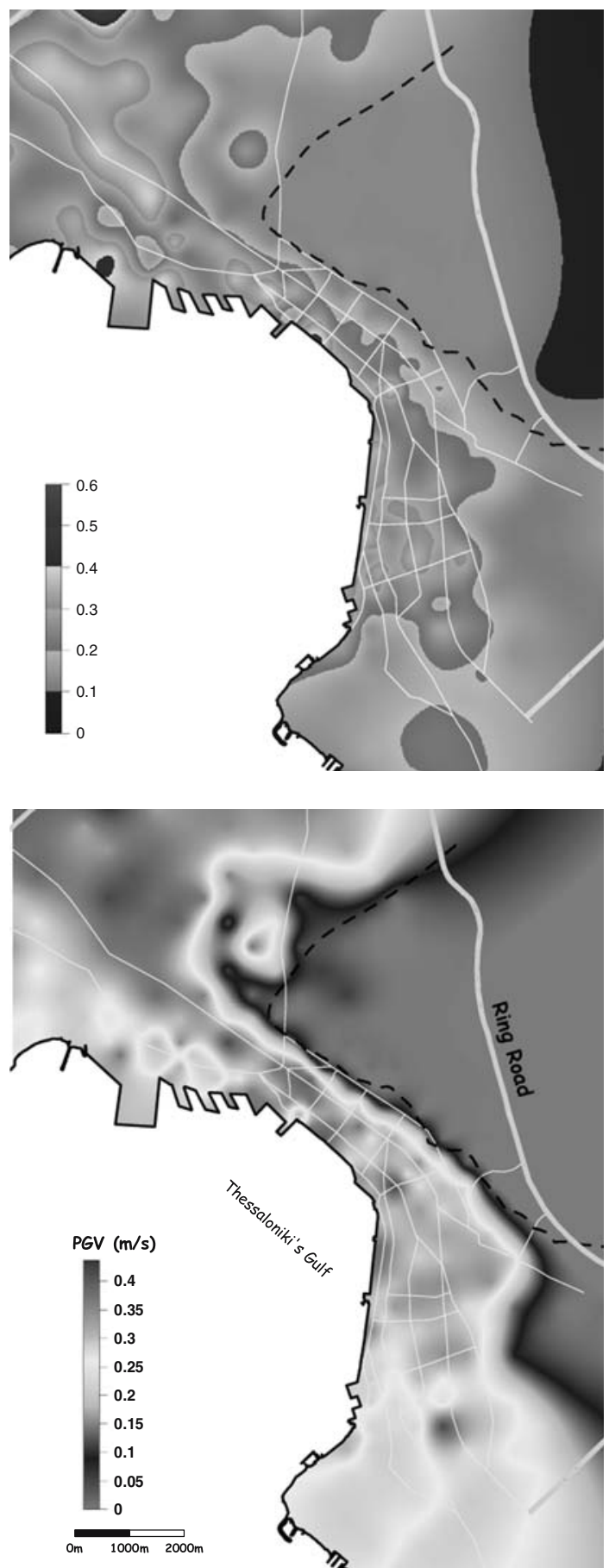
Fig. 6 Thessaloniki: Spatial distribution of mean strain values $(\%)$ in $z=-3 \mathrm{~m}$
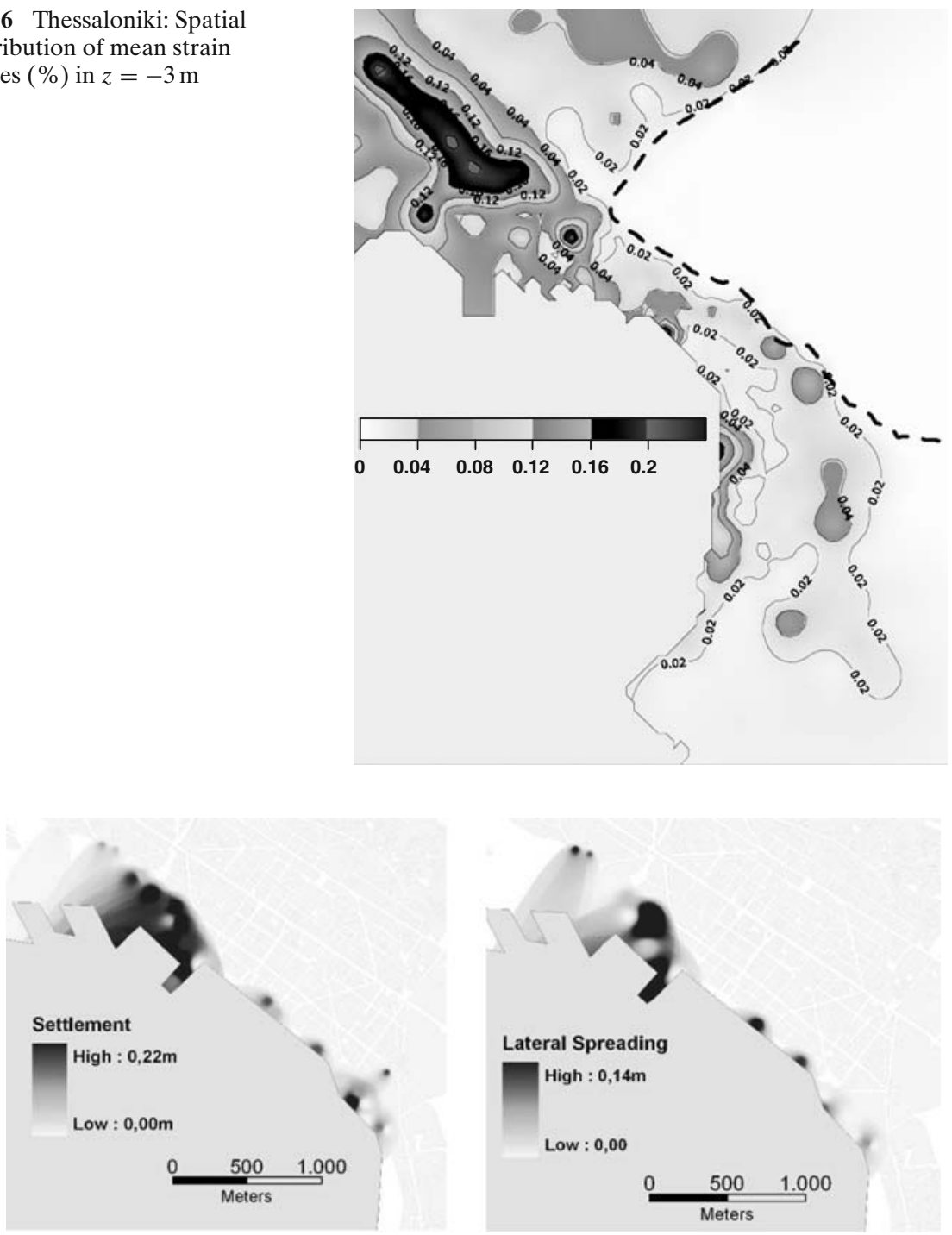

Fig. 7 Thessaloniki: Estimated settlements and lateral spreading due potential liquefaction for a 475-year recurrence period in the coastal zone of the central city

\section{Global value}

The classification of the relative importance of different parts of a lifeline system inside the urban fabric is necessary to evaluate the direct and indirect losses for a specific seismic scenario and to propose adequate mitigation strategies.

International practice usually identifies the strategic/important issues for three main periods of urban functioning: normal, crisis (during and few hours after the earthquake) and recovery (that extents after the disaster). RISK-UE adopted the above practice and extents it to include the functional and social vulnerability, Springer 
Fig. 8 Catania: Spatial distribution of response spectral acceleration for period $T=0\left(a_{\max } \cdot\right)$, including effects of soil conditions, for level I scenario earthquake (Faccioli 2005)
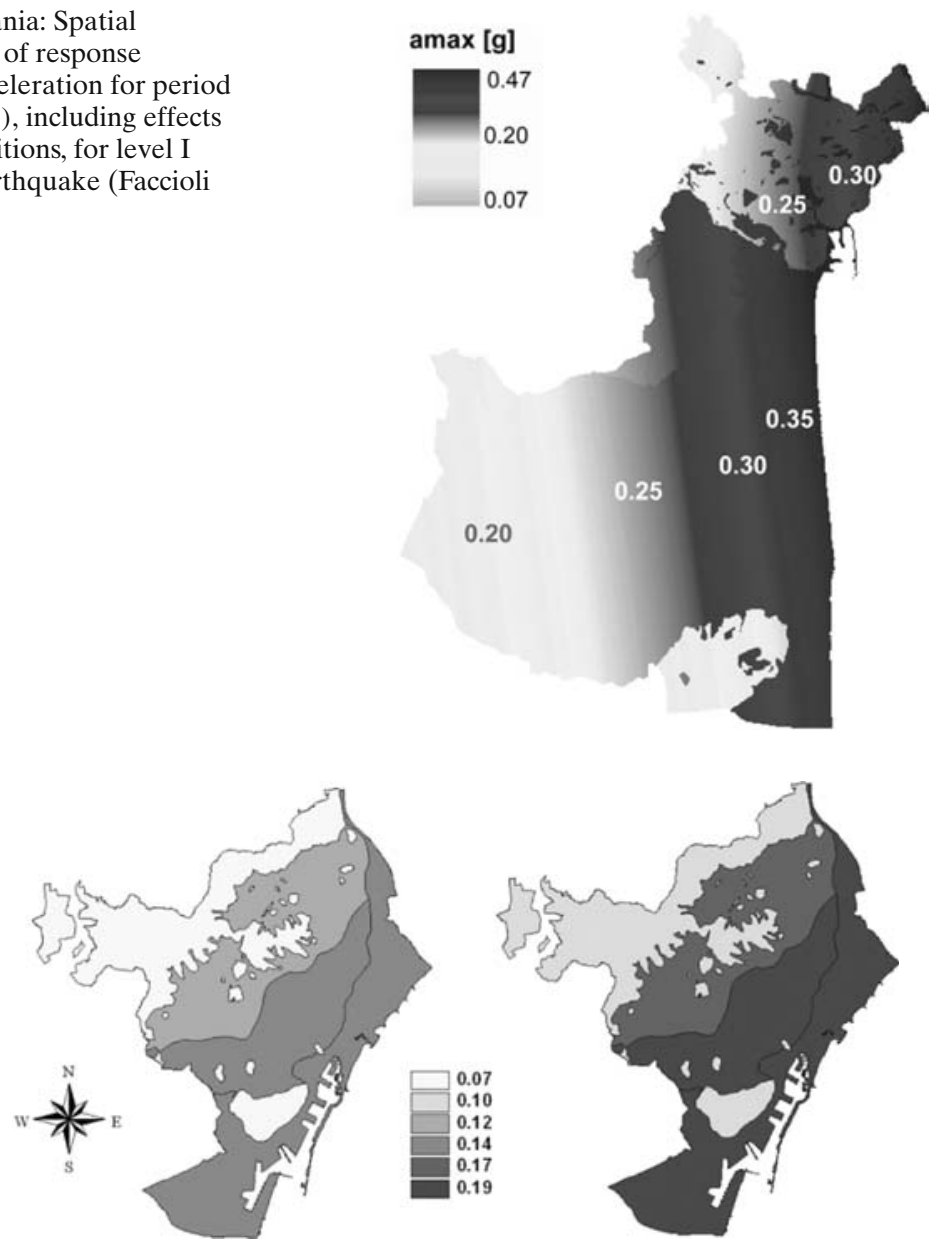

Fig. 9 Barcelona: Spatial distribution of spectral acceleration values at $T=0.0 \mathrm{~s}$ based on deterministic (left) and probabilistic (right) approach for a return period of 475 years

the functional relations between different elements, the urban activities (production, consumption, exchanges) and the relations of the lifeline networks with their surrounding urban or rural environment. This way, each lifeline network is analyzed as an integrated part of the seismic risk scenario and as a part of the urban system, composed of human, material and immaterial elements at risk. In addition, the main issues of the lifeline system are identified according to various factors that describe the role of each element in the urban global system. Crude estimations for three periods of functioning (normal, crisis and restoration) based on generic approach of grouping lifeline elements according to similar characteristics were used to define the "weak points" of lifeline systems according to specific seismic scenarios and particular characteristics of the urban environment. To achieve this, it is proposed to define appropriate qualitative or quantitative indicators for each one of the three periods and to evaluate the global value per element at risk using value scaling factors relevant to measuring units, (Masure and Lutoff 2003). A simple expert mechanism for 
supporting decision-making processing for risk management of water system was also proposed in Alexoudi et al. (2005). Alexoudi (2005) presents also specific indicators and supporting decision-making processing for waste-water, gas and telecommunication systems.

The basic steps for the evaluation of "urban system exposure" and global value for lifelines involve the analysis of every system in its components, the selection of appropriate descriptive indicators together with their relative weight for the three operation periods, the estimation of the global value of each part of the lifeline network and finally, which is the ultimate scope of this analysis, the classification of every part and sub-component of each lifeline network in three categories: main, important and secondary. Failure of a secondary element is less important and does not affect the operation level and serviceability of the whole system, while failure of a main component may affect the whole system.

The selection of adequate indicators is an important part of the proposed methodology. For example in the case of water conduits the selected indicators are: function (supply depending on the diameter) emergency (SCADA or other system), connection with fire fighting system, connection with essential facilities (i.e., hospitals, temporary settlement camps) and relative radiance (i.e., urban use). An application illustrating the final output of the proposed methodology is given in Figs. 10 and 11 for the Thessaloniki water and gas systems respectively.

\section{Interactions}

Interaction means a mutual or reciprocal action or influence. High dependence between lifelines and essential facilities may be very important and can develop a chain of consequences due to individual damages. In RISK-UE four types of interactions between lifelines systems have been used adopted from Kameda (2000) (Physical damage propagation, functional damage propagation, recovery interruption and back-up functions of substitute systems). Interactions may seriously affect the previous global value estimates. Table 4 provides a short reminder of the influence according to the systems involved, the direction of the influence (to have influence on/to be influenced by), the effective time of influence (before/during/after an earthquake) and its importance (slight/strong). Interactions are referring to the previously defined operation periods, while small and capital letters distinct slight or stronger interactions respectively.

\section{Vulnerability curves}

A fundamental requirement for assessing the seismic performance of a system is the ability to quantify the potential damage as a function of the level of seismic hazard intensity. The vulnerability assessment is usually performed introducing appropriate fragility curves developed for every lifeline component. Fragility functions for each element at risk are defined based on empirical, analytical, expert judgment procedures. In Europe although in the past 30 years several strong earthquakes occurred especially across the Mediterranean region, only for Bucharest (1977), Montenegro (1980), Kocaeli-Duzce (1999) and Lefkas (2003) earthquakes brief reports for the lifeline damage are available. 
Fig. 10 Thessaloniki:

Definition of main, important and secondary issues for water system based on global value analysis in different operation periods (a) normal (b) crisis and (c) recovery
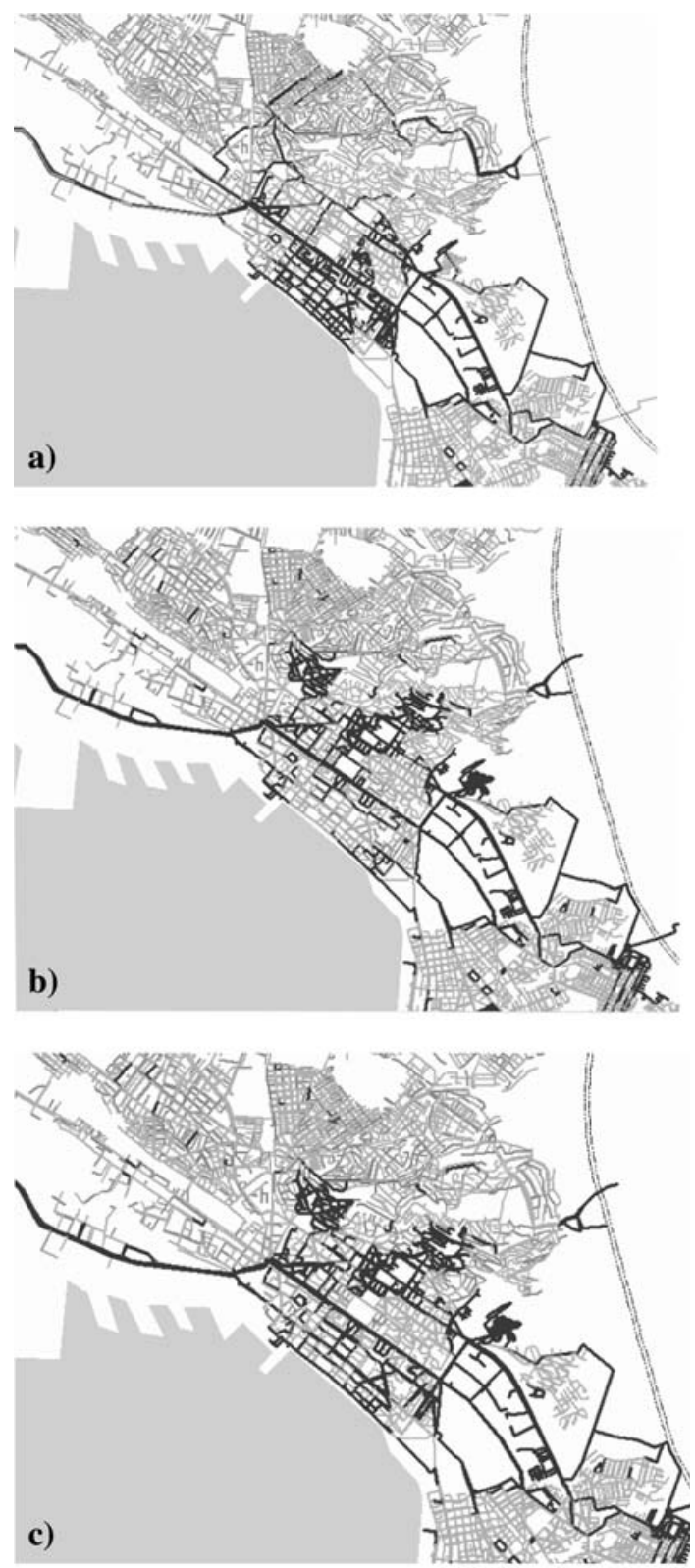

Legend

- Main

- Important

- Secondary 

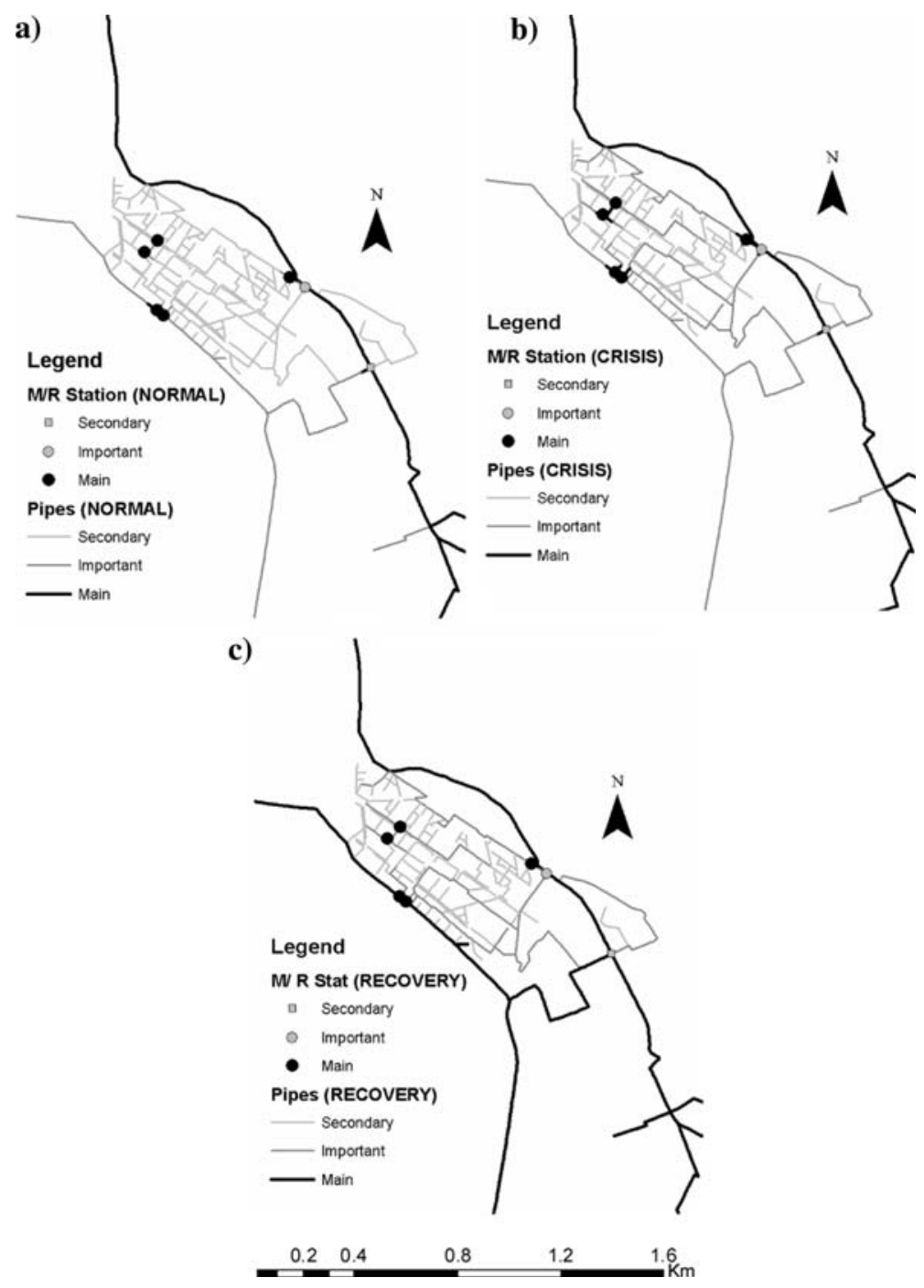

Fig. 11 Thessaloniki: Definition of main, important and secondary issues for gas system based on global value analysis in different operation periods (a) normal (b) crisis and (c) recovery

In the framework of this project, several fragility curves of international bibliography were compared to each other and validated with available damage data. As an example, several researchers proposed empirical fragility curves either for wave propagation (O'Rourke and Ayala 1993, Eidinger 1998, Eidinger and Avila 1999, Isoyama et al. 1998, ALA 2001a,b) or for PGD (Honegger and Eguchi 1992, Eidinger and Avila 1999, ALA 2001a,b) for water and gas pipelines. Such relations correlate ground motions parameters with the Repair Rate/km for pipeline (Table 5, Fig. 12). Important differences are observed, due to the assumptions made by different researchers, the type of correlation analyses, the method of estimating the PGV and PGD in each case, the accuracy of damage data, the seismotectonic background, the 
Table 4 Reminder of possible interaction between the different systems

\begin{tabular}{|c|c|c|c|c|c|c|c|c|c|}
\hline \multirow{2}{*}{$\begin{array}{l}\text { Influence } \\
\text { on }\end{array}$} & \multicolumn{9}{|c|}{ Influenced by } \\
\hline & 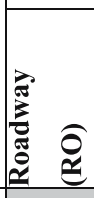 & 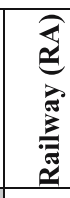 & 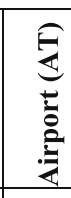 & 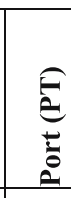 & 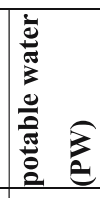 & 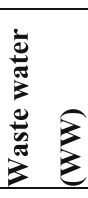 & $\underset{\substack{0 \\
\tilde{E}}}{0}$ & 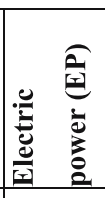 & 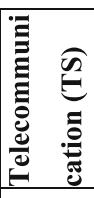 \\
\hline $\begin{array}{l}\text { Roadway } \\
\text { (RO) }\end{array}$ & & $\mathrm{n}, \mathrm{r}^{\mathrm{a}}$ & $n, r$ & $n, r$ & $\mathrm{c}, \mathrm{r}$ & $\mathrm{c}, \mathrm{r}$ & $\mathrm{c}, \mathrm{r}$ & $\mathrm{N}, \mathrm{c}, \mathrm{r}$ & $\mathrm{n}, \mathrm{c}, \mathrm{r}$ \\
\hline $\begin{array}{l}\text { Railway } \\
\text { (RA) }\end{array}$ & $\begin{array}{l}\mathrm{N}, \mathrm{C}, \\
\mathrm{R}\end{array}$ & & $\mathrm{n}, \mathrm{r}$ & $\mathrm{n}, \mathrm{r}$ & $\mathrm{n}, \mathrm{c}, \mathrm{r}$ & $\mathrm{n}$ & $\mathrm{n}$ & $\mathrm{N}, \mathrm{c}, \mathrm{R}$ & $\mathrm{N}, \mathrm{c}, \mathrm{R}$ \\
\hline $\begin{array}{l}\text { Airport } \\
\text { (AT) }\end{array}$ & $\begin{array}{l}\mathrm{N}, \mathrm{C}, \\
\mathrm{R}\end{array}$ & $\mathrm{n}, \mathrm{r}$ & & | & $\mathrm{n}, \mathrm{c}, \mathrm{r}$ & $\mathrm{n}$ & $\mathrm{n}$ & $\mathrm{N}, \mathrm{c}, \mathrm{R}$ & $\mathrm{N}, \mathrm{c}, \mathrm{R}$ \\
\hline Port (PT) & $\begin{array}{l}\mathrm{N}, \mathrm{C}, \\
\mathrm{R}\end{array}$ & $n, r$ & / & & $\mathrm{n}, \mathrm{c}, \mathrm{r}$ & $\mathrm{n}$ & $\mathrm{n}$ & $\mathrm{N}, \mathrm{c}, \mathrm{R}$ & $\mathrm{N}, \mathrm{c}, \mathrm{R}$ \\
\hline $\begin{array}{l}\text { Potable } \\
\text { water } \\
(\mathbf{P W})\end{array}$ & $\begin{array}{l}\mathrm{n}, \mathrm{C}, \\
\mathrm{R}\end{array}$ & / & | & / & & $\mathrm{n}, \mathrm{c}, \mathrm{r}$ & $\mathrm{n}, \mathrm{c}, \mathrm{r}$ & $\mathrm{N}, \mathrm{c}, \mathrm{R}$ & $\mathrm{N}, \mathrm{c}, \mathrm{R}$ \\
\hline $\begin{array}{l}\text { Waste } \\
\text { water } \\
(W W)\end{array}$ & $\begin{array}{l}\mathrm{n}, \mathrm{C}, \\
\mathrm{R}\end{array}$ & / & / & / & / & & $\mathrm{n}, \mathrm{c}, \mathrm{r}$ & $\mathrm{N}, \mathrm{c}, \mathrm{R}$ & $\mathrm{N}, \mathrm{c}, \mathrm{R}$ \\
\hline Gas (GS) & $\begin{array}{l}\mathrm{n}, \mathrm{C}, \\
\mathrm{R}\end{array}$ & $\mathrm{r}$ & $\mathrm{r}$ & $\mathrm{N}, \mathrm{R}$ & $\mathrm{n}, \mathrm{C}, \mathrm{r}$ & $\mathrm{n}, \mathrm{c}, \mathrm{r}$ & & $\mathrm{N}, \mathrm{c}, \mathrm{R}$ & $\mathrm{N}, \mathrm{C}, \mathrm{R}$ \\
\hline
\end{tabular}

influence of site effects, the typology of the pipelines and construction practices and the reliability of pipeline inventory.

The above fragility relations were validated using reported damage data from Duzce $\left(M_{\mathrm{S}}=7.3,12 / 11 / 1999\right.$, Turkey $)$ and Lefkas earthquake $\left(M_{\mathrm{s}}=6.4,14 / 08 / 2003\right.$, 
Table 5 Fragility relationships for pipelines

Ground shaking Ground failure

O’Rourke and Ayala (1993): K*(10-4*PGV $\left.{ }^{2.25}\right)$, $\mathrm{K}$ : type (fragile, ductile)

$\begin{array}{llcr}\text { Honegger and } & \text { Eguchi } & \text { (1992): } \\ \mathrm{K} *\left(7.821 * \mathrm{PGD}^{0.56}\right), & \text { K:type } & \text { (fragile, } \\ \text { ductile) } & & \\ \text { Eidinger and } & \text { Avila } & \text { (1999): } \\ \mathrm{K}_{2} * 23.674 *(\mathrm{PGD})^{0.53} & & \end{array}$

Eidinger (1998): $\quad 1,2 * 10^{-3} * \mathrm{PGV}^{0.7677}$ asbestos-cement, $6 * 10^{-4} * \mathrm{PGV}^{1.5542}$ cast-iron, $6 * 10^{-5 *} \mathrm{PGV}^{2.2949}$ ductile iron

Eidinger and Avila (1999): $\mathrm{K}_{1} * 1.512 *\left(\mathrm{PGV}^{1.98}\right)$,

$\mathrm{K}_{2}$ : material, connection type

$\mathrm{K}_{1}$ : material, connection type, soil, diameter

Isoyama et al. (1998): $\mathrm{Cp} * \mathrm{Cd} * 3.11 * 10-3 *(\mathrm{PGV}$ -

5) ${ }^{1.3}, \mathrm{Cp} \& \mathrm{Cd}$ : material, diameter

ALA (2001a, b): $\mathrm{K}_{1} * 0.241 * \mathrm{PGV}$,

$\mathrm{K}_{1}$ : material, connection type, soil, diameter

ALA (2001a, b): $\mathrm{K}_{2} * 11.223 * \mathrm{PGD}^{0.319}$,

$\mathrm{K}_{2}$ : material, connection type
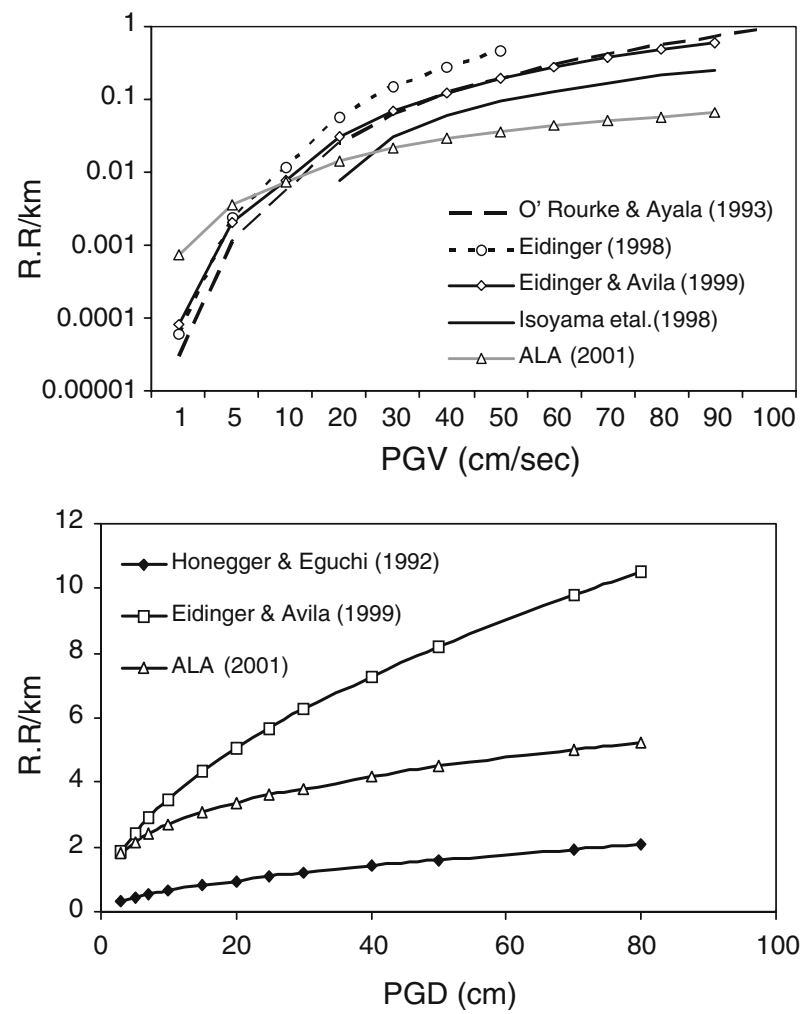

Fig. 12 Comparison between different empirical vulnerability relations for ductile pipes for ground shaking ( $P G V$ left) and permanent ground deformations ( $P G D$ right) 


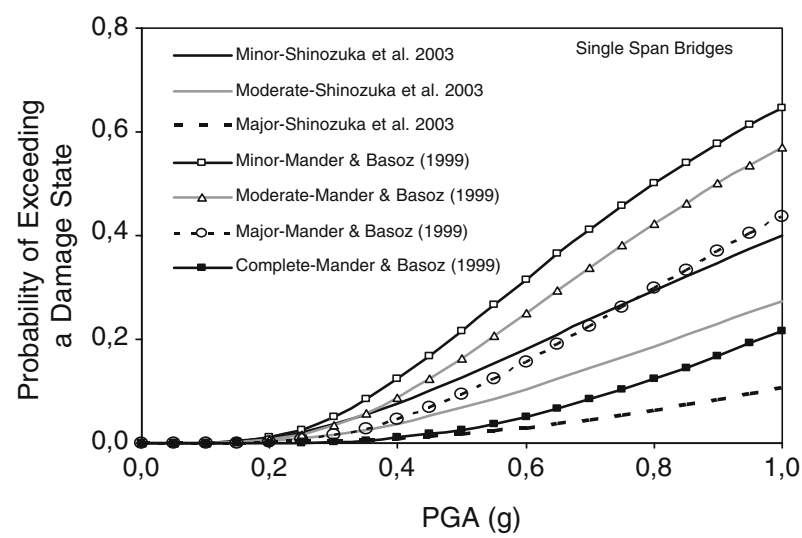

Fig. 13 Comparison between empirical and analytical fragility curves for single span R/C bridges

Greece), (Alexoudi 2005; Pitilakis et al. 2005b). Based on these validations it was found that the ALA (2001a,b) relationships for water/waste-water system and Isoyama et al. (1998) for gas system are most suitable for the European distinctive features.

Another typical comparative example is given in Fig. 13 presenting fragility curves for single span $\mathrm{R} / \mathrm{C}$ bridges. The comparison was made between empirical (Shinozuka et al. 2003) and analytical (Mander and Basoz 1999) fragility curves. It is observed that the analytical curves, which have been also introduced in HAZUS methodology, overestimate the damage state probability for this type of bridges. In Europe there are few analytical-numerical studies proposing fragility curves for some typical European types of bridges (Flesch et al. 1998; GNDT 2000). Further studies are needed to complete all possible typologies.

Consequently, RISK-UE proposed to use fragility curves, mainly derived from existing curves from international bibliography (e.g., NIBS 1999, 2004; ALA 2001a,b) when no appropriate curves are available in Europe.

\section{Vulnerability assessment}

An important issue for the vulnerability assessment of lifeline is the definition of damage state. The most common way to define earthquake consequences of individual lifeline components is a classification in terms of damage states: No damageSlight/minor-Moderate-Extensive-Complete. This approach requires an agreement about the definition and the content of each damage state and this is not always a straight forward procedure. In general the definition of damage states is rather subjective. Thus, alternative expressions, usually called functional states, are also suggested, possibly reflecting better the damages consequence for a specific seismic scenario than previous damage states:

Typically the alternative expressions are defined as:

- Functionality

- Serviceability

- Nominal use, reduced use or not usable; 
Table 6 Different damage state definitions for water source subject to earthquake

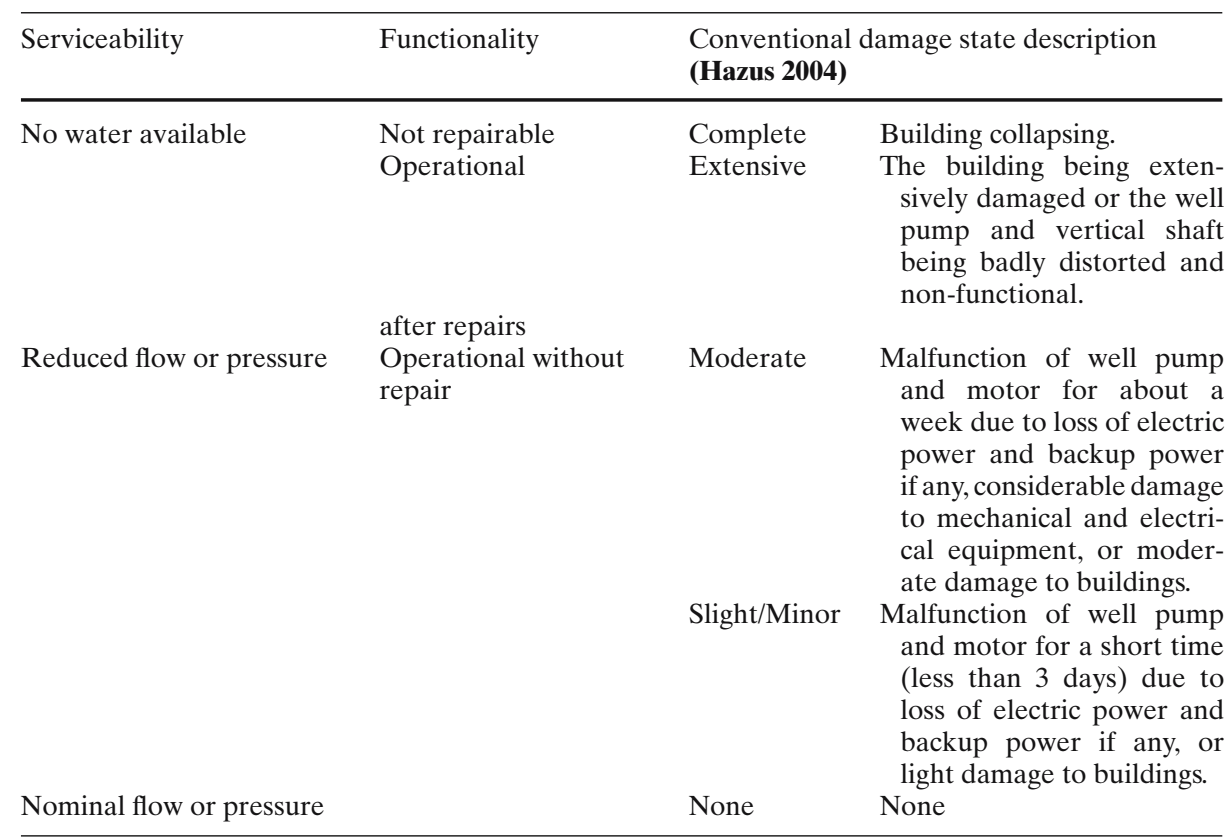

- Usable without repairs, after repairs or not repairable.

- Damage factor or replacement cost (usually between $0 \%$ and $1 \%$ or $100 \%$ ).

Evaluation of these functional states is useful to understand the impact of lifeline response in the emergency and post earthquake responses. An example of damage state definition according to different approaches for water source is given in Table 6 .

Based on the selected fragility curves, vulnerability assessment studies have been performed in the case studies cities for the seismic scenario with 475 years reccurence period. All vulnerability studies have been implemented in GIS environment, while different thematic maps were produced showing the distribution of the expected damages of individual components.

Figures 14 and 15 illustrate an example of damage estimation for the bridges and the water system in Thessaloniki based on the results of natural hazard assessment. The spatial distribution of the spectral acceleration values at $T=1.0 \mathrm{~s}$ and the peak ground velocities together with the estimated PGD values were utilized for the vulnerability assessment of the bridges and water pipelines respectively. It is shown that the majority of bridges will perform rather in a satisfactory way, but there are still few bridges in the western part of the city, which are expected to sustain serious damage for the specific seismic hazard scenario. This is due to the higher vulnerability of these bridges (single column, simple support bridges and inadequate seismic design) and the higher values of the expected surface spectral acceleration because in this area the soil conditions are deep soft alluvium deposits, sandy-silty clays to clayey sandssilts, with low strength and high compressibility, (category C and D in EC8), thus the ground shaking presents stronger amplification at longer periods. 


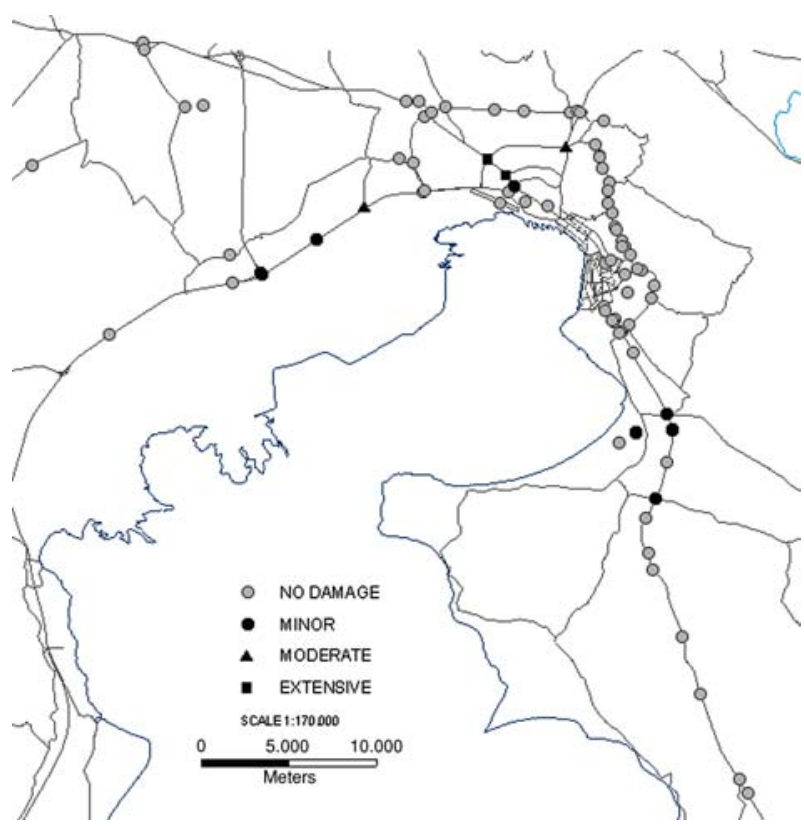

Fig. 14 Thessaloniki: Distribution of damages to R/C bridges (scenario of 475 years recurrence period)

In Fig. 16 is presented another application example for the vulnerability assessment of the gas and water system in Catania based on the PGV values estimated for a deterministic earthquake scenario (Faccioli et al. 2004). The distribution of repair rate for water system shows that the network is expected to suffer 13 ruptures on a total length of $220 \mathrm{~km}$, while the network of gas mains is estimated to suffer two ruptures on a total length of $37 \mathrm{~km}$.

\section{Network/reliability analysis}

There are co-seismic and post seismic criteria describing the performance of any lifeline systems. Co-seismic criteria quantify the component's structural performance according to certain predefined standards in terms of density of damage (\%), connectivity or serviceability analysis. In RISK-UE, a density of lifelines damage is given for each of lifeline component according to available information while in some cities more advanced approaches were made.

An important issue in case of risk analysis of roadway networks in urban areas with high built-up density is the reduction of traffic flow or the blockage of roads due to debris of collapsed buildings and consequently the prevention of rescue and restoration activities. Within RISK-UE a preliminary approach is proposed in order to define the level of road's obstruction due to the adjacent building collapses. Building damages and collapses were estimated using specific vulnerability functions and relative inventories. Detailed presentation of the RISK-UE approach for the vulnerability assessment of buildings may be found in the final RISK-UE reports and in 


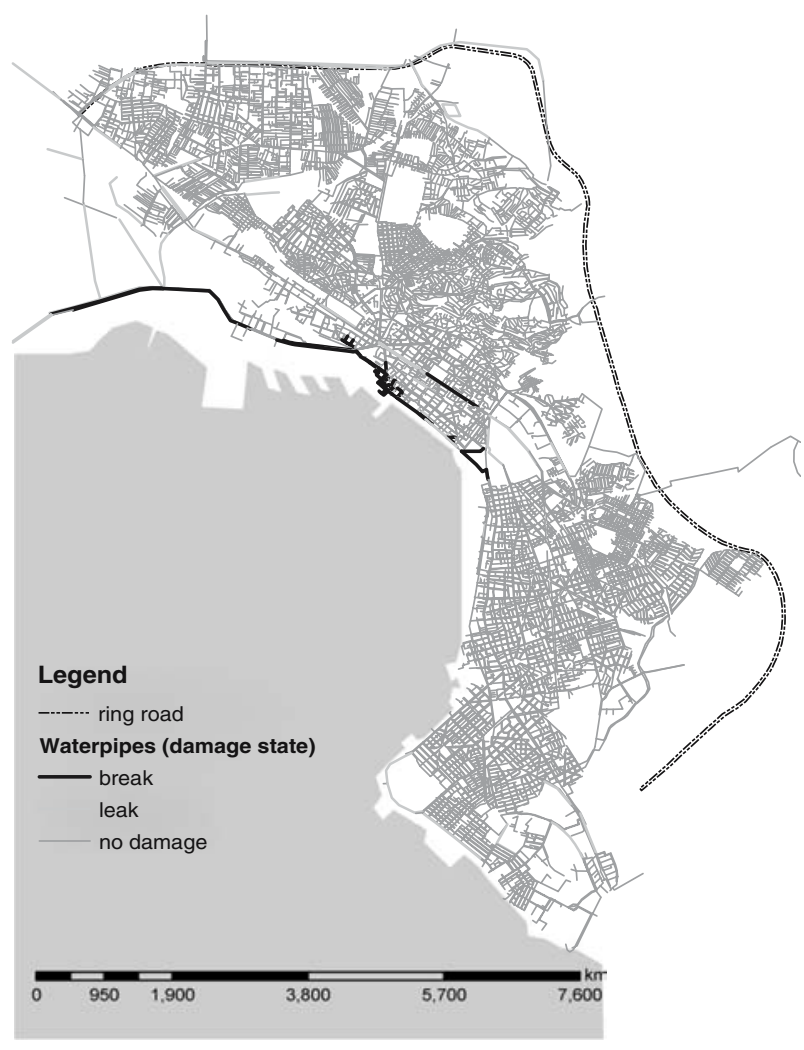

Fig. 15 Thessaloniki: Distribution of damages to water system (scenario of 475 years recurrence period)

related papers in this journal (Lagomarsino and Giovinazzi 2005, Kappos et al. 2005). Simple, yet realistic, collapse shapes are assumed in order to define a relationship between the building's height (i.e., number of storeys) and the width of the induced debris. Based on the damage assessment of buildings and the traffic data, it is possible to estimate the serviceability of the roadway network for a certain seismic scenario and to develop efficient emergency response and recovery planning. In Fig. 17 an example for the city of Catania is presented (Faccioli et al. 2004), where escape routes are identified during the crisis period, based on minimum network travel distance and considering both the extent and the location of damage.

\section{Losses}

The losses from a destructive earthquake are distinguished as direct and indirect. The estimation of direct losses is usually based on the repair or replacement cost of the damaged element while indirect losses is closely connected with reduction of production and other economic and social impacts. RISK-UE in its present stage is not intending to propose models for economical and other indirect. This important part will be one of the major future developments. 


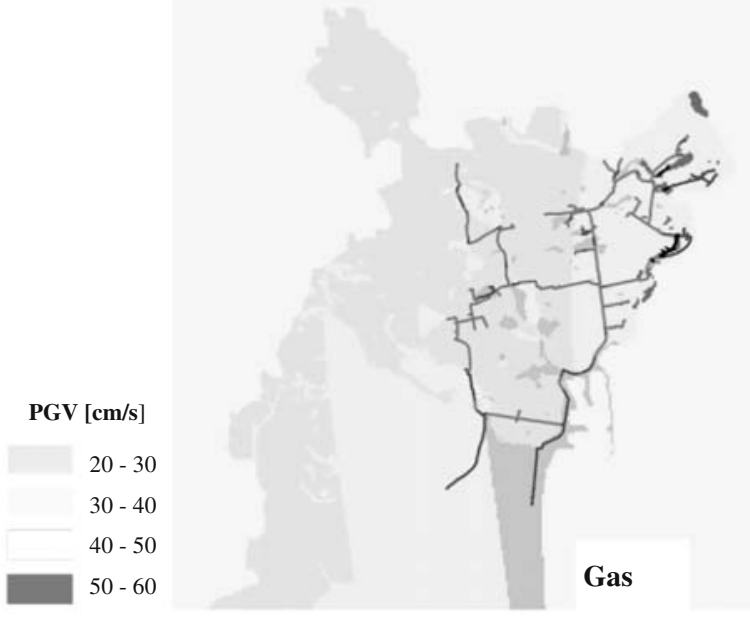

RR

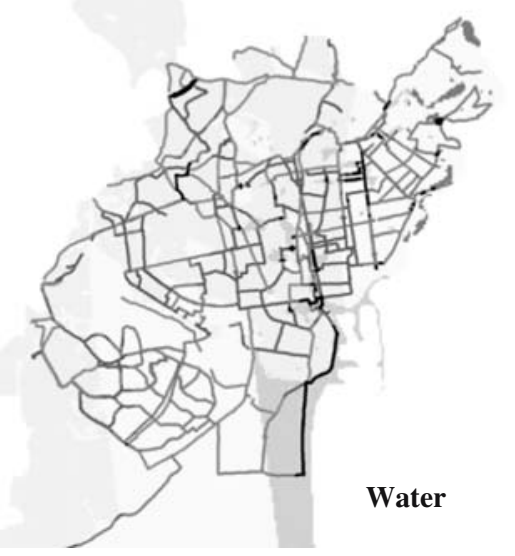

Fig. 16 Catania: Seismic damage scenario for gas and water mains
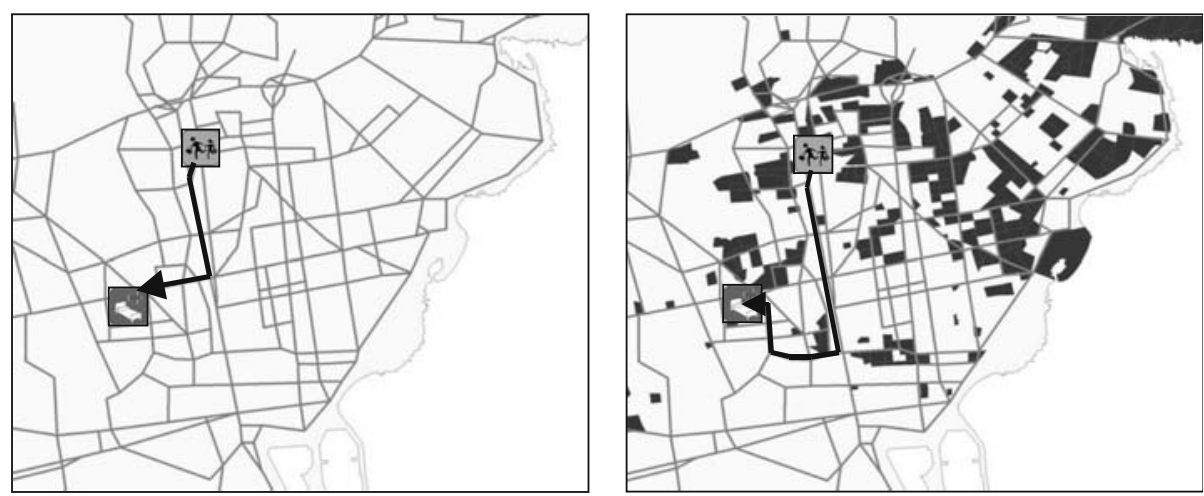

Fig. 17 Catania: Minimum distance between the "XX Settembre" primary school and the Garibaldi hospital before (left) and after the earthquake (right) 


\section{Restoration policy -mitigation strategy}

Mitigation strategy includes pre-earthquake actions and an efficient restoration policy immediately after the seismic event. The pre-seismic identification of the "weak points-and sectors" of a network for a specific seismic scenario and the definition of the "main", "important" and "secondary" elements at risk (parts and sectors of the network) in "normal period", provides a prioritization of the necessary interventions according to the damage state and the importance of each sector of the network. The evaluation of the "global value" in crisis period, the estimation of the vulnerability assessment of the element at risk and the essential human and material resources are indispensable for the development of an efficient recovery plan. Prioritization policies may be defined applying simple double-entrance tables like the one given below for water-pipes (Table 7). An example of a prioritization identification strategy is given in Fig. 18 for the Thessaloniki water system combining the vulnerability assessment and their urban importance.

In a more advanced level, the prioritization policy can be defined through the combination of global value, vulnerability, direct cost and system's reliability. A decision making process of the above factors will define the priorities of the state authorities and lifelines companies. Moreover, in order to decide upon the appropriate mitigation strategy, the expected economic consequences of lifeline damages for a given seismic scenario should be also evaluated. In general if the economic cost (direct and indirect) is limited, the mitigation strategy will be focused then in the restoration process otherwise pre-earthquake risk reduction countermeasures will be indispensable.

Mitigation strategies in the proposed methodology is a straight forward process, as it depends upon the selected seismic scenarios and the lifeline system, the specific inventory, the study period, the importance and the vulnerability of the element at risk. Mitigation strategies can be re-run only if some of the assumptions and requirements differentiate.

\section{Conclusions}

Seismic risk evaluation and management of lifelines is a very sensitive issue in Europe, especially for Mediterranean and Balkan countries where higher seismicity is concentrated. Within RISK-UE project, several steps forward were made to establish a unified European typology and to validate available fragility curves of all elements at risk taking into account the distinctive European features of lifelines. The proposed approach for loss estimation for lifelines estimates the interactions between urban environment and lifelines through an urban global seismic assessment approach as lifeline networks are strongly influenced by urban fabric, economical and the social value of their subcomponents and their individual characteristics. The classification of

Table 7 Risk analysis matrix showing seismic retrofit priorities (Alexoudi et al. 2005)

\begin{tabular}{llll}
\hline Urban Risk/Seismic Risk & \multicolumn{2}{c}{ Issues } & Secondary \\
\cline { 2 - 4 } & Main & Important & 2nd priority \\
\hline Breaks & 1st priority & 1st priority & 3rd priority \\
Leaks & 2nd priority & 3rd priority &
\end{tabular}




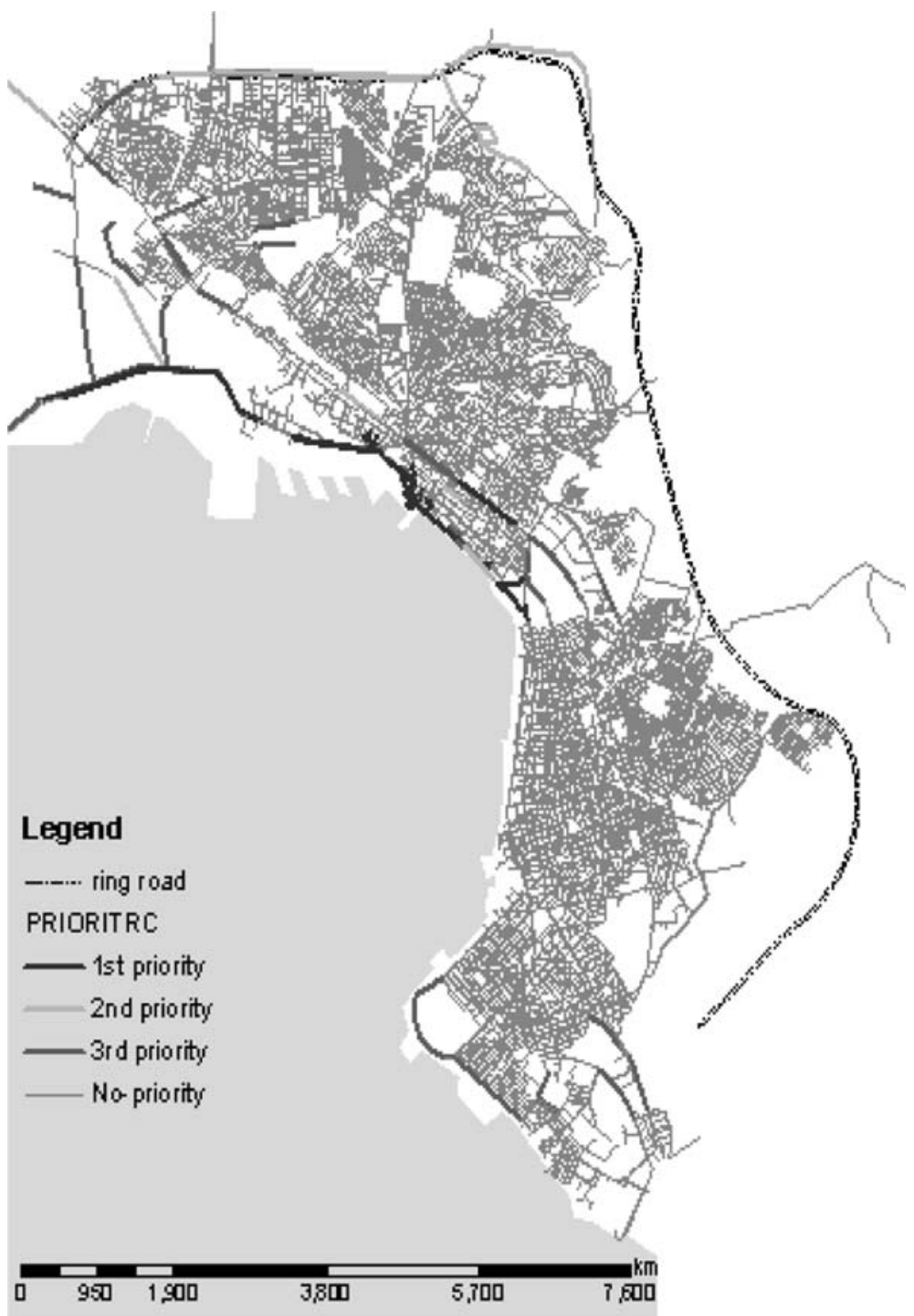

Fig. 18 Thessaloniki: Prioritization strategy for water system restoration for the 475 years recurrence period scenario

the relative importance of lifeline elements (or sectors) through appropriate criteria, using a decision making process for every element of lifeline systems for the three operation periods (normal, crisis and recovery) lead to a more efficient holistic mitigation strategy. An important aspect treated in RISK-UE and shortly presented in this paper is the definition of mitigation priorities based on the estimation of expected damages for a given seismic hazard scenario and the combination of vulnerability and classification of the relative urban importance. The whole approach is developed in a GIS environment, able to produce various thematic maps with the risk analysis results for different seismic scenarios. The cooperation with local authorities, lifeline 
managers and engineers, is necessary to evaluate the priorities defined and to set an efficient European mitigation strategy for lifelines.

Concluding, the proposed approach is a relatively advanced methodology for the seismic risk assessment of lifelines. Previous experience has been used introducing some interesting new ideas regarding the European distinctive features of lifelines, the seismic hazard assessment and the consideration of material and immaterial indicators to estimate losses and mitigation strategies. Further work is still needed especially in the massive damage data collection for lifelines that should be combined with detailed inventory GIS-related databases. Moreover, several steps should be made also in the development of fragility and restoration curves and in the estimation of losses (material and immaterial). Extension of the proposed methodology should include estimation of impacts on a broader scale that uses also network analysis for all lifeline elements.

Acknowledgments The work reported in this paper was carried out within the framework of the RISK-UE project, funded by the European Commission. Part of the work has been performed in the frame of PhD thesis fulfillments of the co-writers S. Argyroudis and M. Alexoudi.

\section{References}

Alexoudi M (2005b) Contribution to seismic assessment of lifelines in urban areas. Development of holistic methodology for seismic risk. PhD Thesis, Department of civil Engineering, Aristotle University of Thessaloniki

Alexoudi M, Hatzigogos Th, Pitilakis K, (2005a) Advanced methodology for mitigation strategy of water system. The case of Thessaloniki (Greece). In: Proceedings of 1st international conference on urban disaster reduction (1ICDR), Kobe, Japan January 18-20

American Lifelines Alliance (2001a) Seismic fragility formulations for water systems. Part 1-Guideline. ASCE-FEMA, $104 \mathrm{pp}$

American Lifelines Alliance (2001b) Seismic fragility formulations for water systems. Part 2-Appendices. ASCE-FEMA, $239 \mathrm{pp}$

American Lifelines Alliance (2002) Development of guidelines to define natural hazards performance objectives for water systems, vol. I. Technical report prepared in by a public-private partnership between FEMA and ASCE, 138 pp

Applied Technology Council (1985) ATC-13-Earthquake damage evaluation data for California. Redwood City, California

Ballantyne DB, Kessler D, Elliott W, Scawthorn Ch (1999) Multi-hazard risk assessment for lifelinesPart 2-case study for the Portland, Oregon water supply system. In: Elliot M, McDonough P (eds) Proceedings, 5th US conference on lifeline earthquake engineering, TCLEE/ASCE, Monograph No.16, 960-969

Chang S, Seligson H (2003) Evaluating mitigation of urban infrastructures systems: application to the Los Angeles department of water and power. In: Beavers JE (ed) Proceedings, 6th US conference and workshop on lifeline earthquake engineering, TCLEE/ASCE, Monograph No.25, 474-483

Eidinger, J (1998) Lifelines, water distribution system in the Loma Prieta, California, Earthquake of October 17, 1989, performance of the build environment-lifelines. In: Schiff A (ed) US geological survey professional paper 1552-A, pp A63-A80

Eidinger J, Avila E (1999) Guidelines for the Seismic upgrade of water transmission facilities. Monograph No. 15, TCLEE/ASCE

Faccioli E, (co-ordinator), Frassine L, Finazzi D, Pessina V, Cauzzi C, Lagomarsino S, (co-ordinator), Giovinazzi S, Resemini S, Curti E, Podestà S, with thecollaboration of Scuderi S (2004) An advanced approach to earthquake risk scenarios with applications to different European towns. Synthesis of the application to Catania city

Faccioli E (2005) Seismic hazard assessment. In: Spence R, Le Brun B (eds) Bulletin of earthquake engineering, special issue: the risk-ue project-methodology

Flesch RG, Duma G, Darin EM, Panza GF, Romanelli F, Cunha A, Barbat A (1998) Advanced methods for assessing the seismic vulnerability of existing motorway bridges (VAB). Project ENV4- 
CT97-0574, DG12 workshop on reducing earthquake risks to structures and monuments in Europe, Cambridge, UK.

Honegger DG, Eguchi RT (1992) Determination of the relative vulnerabilities to Seismic damage for dan diego country water Authority (SDCWA) Water Transmission Pipelines

Huyck Ch, Eguchi R, Watkins R, Seligson H, Bucknam St, Bortugno E (2003) URAMP (Utilities Regional Assessment of Mitigation Priorities) - A Benefit-cost analysis tool for water, wastewater and drainage utilities: software development. In: Beavers JE (ed) Proceedings, 6th US conference and workshop on lifeline earthquake engineering, TCLEE/ASCE, Monograph No.25, 484-493

Isoyama R, Ishida E, Yune K, Shirozu T (1998) Seismic damage estimation procedure for water supply pipelines. In: Proceedings of water \& earthquake '98 Tokyo, IWSA international workshop, anti-seismic measures on water supply, International Water Services Association and Japan Water Works Association, Tokyo Japan

Kameda, H (2000) Engineering management of lifeline systems under earthquake risk. In: Proceedings of the 12th world conference on earthquake engineering, New Zealand Society for Earthquake Engineering, Upper Hutt, NZ

Kappos AJ, Panagopoulos G, Panagiotopoulos Ch, Penelis G (2005) A hybrid method for the vulnerability assessment of R/C and URM buildings. In: Spence R, Le Brun B (eds) Bulletin of earthquake engineering, special issue: the risk-ue Project-Methodology

Kiremidjian A, Moore J, Fan Y, Ozgur Y, Basoz N, Williams M, (2003) The PEER highway demonstration project. In: Beavers JE (ed) Proceedings, 6th US conference and workshop on lifeline earthquake engineering, TCLEE/ASCE, Monograph No.25, 896-905

Lagomarsino S, Giovinazzi S (2005) Macroseismic and mechanical models for the vulnerability assessment of current buildings. In: Spence R, Le Brun B (eds) Bulletin of earthquake engineering, special Issue: the risk-ue project-methodology

Mander J, Basoz N (1999) Seismic fragility curve theory for highway bridges. In: Elliot M, McDonough P (eds) Proceedings, 5th US conference on lifeline earthquake engineering, TCLEE/ASCE, Monograph No.16, pp 31-40

Masure Ph, Lutoff C (2003) An advanced approach to earthquake risk scenarios with applications to different European towns. Urban system analysis (WP03): methodology on urban system exposure assessment to natural disasters, 82 pp (30 Figs., 14 Tables, 1 Appendix)

Monge O, Alexoudi M, Argyroudis S with the coordination and collaboration of Martin C, Pitilakis K (2004) RISK-UE. An advanced approach to earthquake risk scenarios with applications to different European towns. Vulnerability assessment of lifelines and essential facilities (WP06): basic methodological handbook. Report n ${ }^{\circ}$ GTR-RSK 0101-152av7, 71 pp (13 Figures, 27 Tables, 11 Appendices)

Mouroux P, Bertrand E, Bour M, Le Brun B, Depinois S, Masure P (2004) The European RISKUE project: an advanced approach to earthquake risk scenarios. Proceedings of the 13th world conference on earthquake engineering, Vancouver, BC, Canada, paper 3329 (CD-Rom)

National Institute of Building Sciences $(1999,2004)$ Direct physical damage to lifelines-transportation systems-utility systems. Earthquake loss estimation methodology. HAZUS Technical manual, vol. 2. Chapters 7, 8. Federal Emergency Management Agency, Washington, D.C.

O'Rourke M, Ayala G (1993) Pipeline damage due to wave propagation. J Geotec Eng, ASCE 119(9): 1490-1498

Pachakis D, Kiremidjian AS (2004) Estimation of downtime-related revenue losses in seaports following scenario earthquakes. Earthquake Spectra 20(2):427-449

Pavese A (ed) (2000) Valutazione della vulnerabilita sismica dei ponti di Catania. CNR-Gruppo Nazionale per la Difesa dai Terremoti-Roma, $172 \mathrm{pp}$

Pitilakis K (2004) Chapter 5: Site effects. In: Ansal A (ed) Recent advances in earthquake geotechnical engineering \& microzonation, Kluwer Publications

Pitilakis K, Alexoudi A, Argyroudis S, Monge O, Martin C (2005a) Chapter 9: vulnerability assessment of lifelines. In: Goula X, Oliveira CS, Roca A (eds) Assessing and Managing Earthquake Risk Springer Publications, ISBN 1-4020-3524-1

Pitilakis K, Alexoudi M, Kakderi K, Manou D, Batum E, Raptakis D (2005b) Vulnerability analysis of water systems in strong earthquakes. The case of Lefkas (Greece) and Duzce (Turkey). In: International symposium on the geodynamics of eastern mediterranean: active tectonics of the Aegean, Istanbul, Turkey June 15-18

Reed D, Cook C (1999) Multi-hazard analysis of utility lifeline systems. In: Elliot M, McDonough P (eds), Proceedings, 5th US conference on lifeline earthquake engineering, TCLEE/ASCE, Monograph No.16, 940-949 
Roca A (co-ordinator) (2004) An advanced approach to earthquake risk scenarios with applications to different European towns. Synthesis of the application to Catania city

Scawthorn Ch, Ballantyne DB, Eguchi R, Khater M (1999) Multi-hazard risk assessment for lifelinesPart 1 - overview and approach. In: Elliot M, McDonough P (eds) Proceedings, 5th US conference on lifeline earthquake engineering, TCLEE/ASCE, Monograph No.16, 950-959

Seligson H, Ballantyne D, Huyck Ch, Eguchi R, Bucknam St, Bortugno E, (2003) URAMP (Utilities Regional Assessment of Mitigation Priorities) - a benefit-cost analysis tool for water, wastewater and drainage utilities: methodology development. In: Beavers JE (ed) Proceedings, 6th US conference and workshop on lifeline earthquake engineering, TCLEE/ASCE, Monograph No.25, 494-503

Shinozuka M, Feng MQ, Kim H-K, Uzawa T, Ueda T (2003) Statistical analysis of fragility curves. Technical report MCEER-03-0002, State University of New York, Buffalo

Werner SD, Taylor CE, Moore JE, Walton JS, Cho S (2000) A risk-based methodology for assessing the seismic performance of highway systems. Technical report MCEER-00-0014, State University of New York, Buffalo 